\title{
Retinoid signaling controlled by SRC-2 in decidualization revealed by transcriptomics
}

\author{
Maria M Szwarc ${ }^{1}$, Lan Hai ${ }^{1}$, William E Gibbons², Lisa D White ${ }^{3}$, Qianxing Mo ${ }^{4}$, \\ Ramakrishna Kommagani ${ }^{5}$, Rainer B Lanz ${ }^{1}$, Francesco J DeMayo ${ }^{6}$, Bert W O'Malley ${ }^{1}$ and \\ John P Lydon ${ }^{1}$
}

${ }^{1}$ Department of Molecular \& Cellular Biology, Baylor College of Medicine, Houston, Texas, USA, ${ }^{2}$ Department of Obstetrics \& Gynecology, Baylor College of Medicine, Houston, Texas, USA, ${ }^{3}$ Departments of Molecular \& Human Genetics and Molecular \& Cellular Biology, Genomic \& RNA Profiling Core Facility, Baylor College of Medicine, Houston, Texas, USA, ${ }^{4}$ Department of Medicine and Dan L. Duncan Cancer Center, Baylor College of Medicine, Houston, Texas, USA, ${ }^{5}$ Department of Obstetrics \& Gynecology, Washington University School of Medicine, St Louis, Missouri, USA and ${ }^{6}$ Reproductive and Developmental Biology Laboratory, National Institute of Environmental Health Sciences, Research Triangle Park, North Carolina, USA

Correspondence should be addressed to J P Lydon; Email: jlydon@bcm.tmc.edu

\begin{abstract}
Establishment of a successful pregnancy requires not only implantation of a healthy embryo into a receptive uterus but also progesterone receptor (PGR)-dependent transformation of endometrial stromal cells (ESCs) into specialized decidual cells. Decidual cells support the developing embryo and are critical for placentation. We have previously shown that a known transcriptional coregulator of the PGR, steroid receptor coactivator-2 (SRC-2), is a critical driver of endometrial decidualization in both human and mouse endometrium. However, the full spectrum of genes transcriptionally controlled by SRC-2 in decidualizing ESCs has not been identified. Therefore, using an RNA- and chromatin immunoprecipitation-sequencing approach, we have identified the transcriptome of decidualizing human ESCs (hESCs) that requires SRC-2. We revealed that the majority of hESC genes regulated by SRC-2 are associated with decidualization. Over $50 \%$ of SRC-2-regulated genes are also controlled by the PGR. While ontology analysis showed that SRC-2-dependent genes are functionally linked to signaling processes known to underpin hESC decidualization, cell membrane processes were significantly enriched in this analysis. Follow-up studies showed that retinoid signaling is dependent on SRC-2 during hESC decidualization. Specifically, SRC-2 is required for full induction of the retinol transporter, stimulated by retinoic acid 6 (STRA6), which is essential for hESC decidualization. Together our findings show that a critical subset of genes transcriptionally reprogramed by PGR during hESC decidualization requires SRC-2. Among the multiple genes, pathways and networks that are dependent on SRC-2 during hESC decidualization, first-line analysis supports a critical role for this coregulator in maintaining retinoid signaling during progesterone-driven decidualization.

Reproduction (2018) $156387-395$
\end{abstract}

\section{Introduction}

For healthy couples, natural conception is remarkably inefficient with a success rate of only $30-40 \%$ per menstrual cycle (Wilcox et al. 1988, Zinaman et al. 1996, Macklon et al. 2002). While 30\% of these early pregnancy failures are linked to impaired embryo development, $70 \%$ are associated with a dysfunctional uterus during the periimplantation period (Macklon et al. 2002). Periimplantation failure also compromises the full potential of assisted reproductive technologies, which rely on the transfer of healthy embryos into a receptive uterus (Blesa et al. 2014). In addition to the clinical challenges, such early pregnancy losses impose severe emotional distress (Greil et al. 2010) and economic burdens on women and their families worldwide (Chambers et al. 2014).

Formation of the decidua, through a process termed decidualization, is essential for advancement of the implantation process toward placentation (Cha et al. 2012). Decidualization entails the rapid proliferation and differentiation of fibroblastic endometrial stromal cells into polygonal epithelioid decidual cells (Gellersen \& Brosens 2014). While modulating trophectodermal invasion into the maternal compartment that leads to placentation, the decidua also supports the developing embryo by providing histotrophic nutrition and local immunosuppression (Carson et al. 2000, Gellersen et al. 2007). Importantly, inadequate decidualization not only leads to fetal demise at an early stage of gestation but 
can potentially cause adverse pregnancy outcomes in subsequent trimesters (Wang \& Dey 2006, Norwitz et al. 2015). Progesterone (P4), via its cognate nuclear receptor, the progesterone receptor (PGR), is essential for endometrial decidualization (Lydon et al. 1995). Using genome-wide analysis, a number of studies have recently shown that PGR-mediated transcriptional reprogramming of human endometrial stromal cells (hESCs) underpins P4-dependent decidualization of this cell type (Cloke et al. 2008, Mazur et al. 2015). However, little is known concerning the involvement of the transcriptional coregulators that modulate PGR action during this cellular transformation process.

The p160/steroid receptor coactivator (SRC) family consists of three evolutionary conserved coregulators of transcription, termed SRC-1, -2 and -3 (Xu et al. 2009). First discovered as primary coregulators of nuclear receptor (NR)-mediated transcription, SRCs are now known to serve as pleiotropic transcriptional coregulators of a diverse range of non-NR transcription factors (Onate et al. 1995, Voegel et al. 1996, Torchia et al. 1997, Xu et al. 2009). Because of the complex functional domain structure of SRCs, this coregulator class can integrate a myriad of signaling cues that control a broad spectrum of physiological and pathophysiological responses (Xu et al. 2009, Stashi et al. 2014). In the case of the uterus, we and others demonstrated that endometrial SRC-2 is required for early pregnancy establishment in the mouse (Gehin et al. 2002, Mukherjee et al. 2006). Using a conditional knockout mouse, we revealed that SRC-2 is indispensable for P4-dependent endometrial decidualization (Mukherjee et al. 2006). Importantly from a clinical perspective, we also showed that SRC-2 is essential for P4-driven hESC decidualization in vitro (Kommagani et al. 2013). Together, these studies underscored an evolutionary conserved role for SRC-2 in $\mathrm{P} 4-$ dependent decidualization, a role not compensated by SRC-1 and/or SRC-3.

Given that P4-dependent hESC decidualization relies on transcriptional reprogramming and that SRC-2 as a transcriptional coregulator is critical for decidualization, we used RNA sequencing (RNA-seq) to identify the SRC2-responsive transcriptome during this reprogramming event. To showcase the utility of this transcriptome dataset in elucidating new signaling connections with SRC-2 that are important for P4-dependent hESC decidualization, we reveal that full induction of stimulated by retinoic acid 6 (STRA6) expression is dependent on SRC-2 and required for hESC decidualization.

\section{Materials and methods \\ Human subjects}

Human protocols were prospectively approved by the Institutional Review Board at Baylor College of Medicine and were in accordance with the guidelines of the Declaration of Helsinki (WMA 1966) and written-informed consent was obtained from all participating subjects. Isolation of hESCs from endometrial tissue biopsied from women of reproductive age during the proliferative phase of their menstrual cycle has been described in Kommagani et al. (2016).

\section{Cell culture and siRNA transfection}

Unless otherwise stated, cell culture media and reagents were purchased from Thermo Fisher Scientific. Human ESCs were maintained in DMEM/F12 medium containing 10\% fetal bovine serum (FBS; Sigma-Aldrich), penicillin, streptomycin, an antimycotic, sodium bicarbonate and HEPES. Cells were transfected with siRNAs $48 \mathrm{~h}$ after plating into six-well plates at $8 \times 10^{4}$ cells per well. Following complexing of siRNAs with Lipofectamine RNAiMax (Thermo Fisher Scientific) in OptiMEM I Reduced Serum Medium, cells were transfected with siRNAs at 60 pmol per well in MEM with $2 \%$ charcoal-stripped FBS (sFBS; Sigma-Aldrich).

\section{In vitro decidualization}

Following siRNA transfection, hESCs were decidualized with a hormone cocktail of $10^{-8} \mathrm{M} 17 \beta$-estradiol (E2), $10^{-6} \mathrm{M}$ medroxyprogesterone 17-acetate (MPA), and $5 \times 10^{-5} \mathrm{M} \mathrm{N} 6,2^{\prime}$ O-dibutyryladenosine $3^{\prime}, 5^{\prime}$-cyclic monophosphate sodium salt (CAMP) (the hormone deciduogenic stimulus; termed EPC (Sigma-Aldrich)) in Opti-MEM I reduced serum medium with $2 \%$ sFBS. Cells were collected for RNA and/or protein isolation at day 0 and day 3 of EPC treatment.

\section{RNA isolation and sequencing}

Total RNA was prepared with the RNeasy Plus kit (Qiagen). For RNA sequencing, RNA purity and integrity was assessed using a NanoDrop spectrophotometer (Thermo Fisher Scientific) and an Agilent Bioanalyzer 2100 with Agilent RNA Nano 6000 chips, respectively. Sequencing of RNA was performed as described in Szwarc et al. (2018). Briefly, libraries were prepared using TruSeq RNA library preparation kit v2 (Illumina, Inc.) and enriched by PCR. Adapter-ligated fragment concentration was measured by quantitative PCR assay with a KAPA library Quant kit (Kapabiosystems, Inc., Wilmington, MA, USA). Samples were then pooled and quantified again by qPCR. Bridge amplification using the cBot 2 system (Illumina, Inc.) was used for clonal cluster generation of library pools. Indexed paired-end sequencing was performed with the HiSeq 2500 sequencing system (Illumina, Inc.).

\section{Analysis of RNA sequencing data}

Raw reads of 101 nucleotides were trimmed by 11 nucleotides on their $5^{\prime}$ ends to increase mappability. The resulting 90-nucleotide pair-ended reads were mapped to the human genome (UCSC hg19) using STAR (Dobin et al. 2013) with $\mathrm{NCBI}$ RefSeq genes as the reference. Read duplicates were removed using picard tools (http://broadinstitute.github. io/picard/) in order to reduce possible PCR biases. HTseq (http://www-huber.embl.de/users/anders/HTSeq) was used to determine the number of reads falling within known genes 
(Anders et al. 2015). The edgeR package (Robinson et al. 2010) was used to analyze the gene-based read counts to detect differentially expressed genes in the following comparisons: (1) EPC day 3 non-targeting (NT) siRNA vs EPC day 0 NT siRNA; (2) EPC day 0 SRC-2 siRNA vs EPC day 0 NT siRNA and (3) EPC day 3 SRC-2 siRNA vs EPC day $3 N T$ siRNA. The false discovery rate (FDR) of differentially expressed genes was calculated using the Benjamini and Hochberg method (Benjamini \& Hochberg 1995) with FDR <0.05 considered to be statistically significant. Resulting gene sets were gated based on a FDR $<0.05$ and on absolute fold changes ( $|F C|)$ $\geq 1.5$. Gene ontology enrichment analysis was performed using the functional annotation clustering tools in DAVID (Database for Annotation, Visualization, and Integrated Discovery; http:// david.abcc.ncifcrf.gov/) (Huang da et al. 2009). Gene Set Enrichment Analysis (GSEA; http://software.broadinstitute.org/ gsea/) was used to identify overlaps between our filtered gene subsets and hallmark gene set collection in the Molecular Signatures Database (Liberzon et al. 2015).

\section{Chromatin immunoprecipitation followed by sequencing}

Using a ChIP-grade antibody to human SRC-2 (Bethyl Laboratories, Montgomery, TX, USA; A300-346A), chromatin immunoprecipitation followed by sequencing (ChIP-seq) was performed as previously described on chromatin derived from hESCs treated with EPC for 3 days (Mazur et al. 2015, Kommagani et al. 2016).

\section{Quantitative reverse transcriptase PCR}

Reagents for quantitative reverse transcriptase PCR analysis were obtained from Applied Biosystems (AP) (Thermo Fisher Scientific). SuperScript VILO Master Mix was used to prepare cDNA according to the manufacturer's instructions. Resulting CDNAs of interest were quantified by real-time PCR using AP Biosystems QuantStudio 12K Flex Real-Time PCR System in reactions containing AP TaqMan Gene Expression Assays and AP TaqMan Universal Master Mix II. Taqman assays used in this study are listed in Supplementary Table 1 (see section on supplementary data given at the end of this article).

\section{Protein isolation and Western blot}

Protein was extracted from cells with NP40 buffer $(150 \mathrm{mM}$ $\mathrm{NaCl}, 1.0 \% \mathrm{NP}-40,50 \mathrm{mM}$ Tris. $\mathrm{Cl} \mathrm{pH}$ 8.0) with protease inhibitors (complete EDTA-free; Roche Diagnostics). Protein concentration was quantified using Pierce BCA Protein Assay Kit (Thermo Fisher Scientific). Protein (15-25 $\mu \mathrm{g} /$ lane) was resolved by SDS-PAGE (Biorad Laboratories) before transferring to a polyvinylidene fluoride membrane (Millipore). Nonspecific IgG binding was blocked with $5 \%$ milk in Tris-buffered saline with $0.1 \%$ Tween. Immunoreactive bands were detected with the following antibodies: STRA6 (Novus Biologicals, Littleton, CO; H00064220-D01P, diluted 1:1250), $\beta$-actin (Sigma-Aldrich; A1978, diluted 1:10,000). Secondary horse radish peroxidase-conjugated antibodies were purchased from Santa Cruz Biotechnology.

\section{Statistical analysis}

Results are presented as averages \pm standard deviation. Statistical analysis was conducted in $\mathrm{R}$ Studio ( $\mathrm{R}$ Studio Inc., Boston, MA, USA). Normality of data was examined on quantile comparison plots. Calculations of $P$ values were performed with ANOVA with post hoc analysis performed with Tukey's range test; $P>0.05$ were considered as non-significant differences while $P \leq 0.05\left(^{*}\right), P \leq 0.01\left(^{* *}\right)$ and $P \leq 0.001\left(^{* * *}\right)$ were considered significant.

\section{Results}

\section{Identification of genes controlled by SRC-2 in hESCs during decidualization}

To identify genes that are both important for hESC decidualization and transcriptionally dependent on SRC-2, RNA-seq was performed on the following hESC RNA samples in triplicate: (1) cells transfected with NT siRNA collected at day 0 of EPC treatment (NT siRNA day 0 EPC); (2) cells transfected with SRC-2 siRNA collected at day 0 of EPC treatment (SRC-2 siRNA day 0 EPC); (3) cells transfected with NT siRNA collected at day 3 of EPC treatment (NT siRNA day $3 \mathrm{EPC}$ ) and (4) cells transfected with $S R C-2$ siRNA collected at day 3 of EPC treatment (SRC-2 siRNA day 3 EPC). Principal component analysis (Supplementary Fig. 1A and B) revealed that individual experimental samples were primarily grouping based on the time-point of EPC treatment (day 0 and 3 of EPC treatment). From the resultant RNA-seq data, paired comparisons were performed to reveal the following gene expression changes: (1) NT siRNA day 3 EPC vS NT siRNA day 0 EPC: to reveal gene expression changes which occur during decidualization; (2) SRC2 siRNA day 0 EPC vs NT siRNA day 0 EPC: to detect gene expression affected by SRC-2 knockdown before the onset of decidualization and (3) SRC-2 siRNA day 3 EPC vs NT siRNA day 3 EPC: to identify gene expression changes caused by SRC-2 knockdown at day 3 of EPC (decidualization). After applying analytical cut-offs of $|\mathrm{FC}| \geq 1.5$ and $\mathrm{FDR}<0.05$, the expression of over 5552 RefSeq genes was found to be significantly altered during decidualization (Fig. 1A; NT siRNA day 3 EPC vs NT siRNA day 0 EPC). The number of genes and the degree of gene expression changes with day 3 EPC (decidualization) treatment are in agreement with our previously published decidual control dataset (Szwarc et al. 2018), which served as a quality control for our current study (Supplementary Fig. 1C). The full list of gene expression changes in all three datasets is found in Supplementary data 1.

Knockdown of SRC-2 caused significant changes in expression of 385 and 326 genes at day 0 and day 3 of EPC treatment, respectively (Fig. 1A). Over half of the genes transcriptionally regulated by SRC-2 are also induced or repressed during EPC-induced decidualization. While the most robust changes in gene expression occur during 


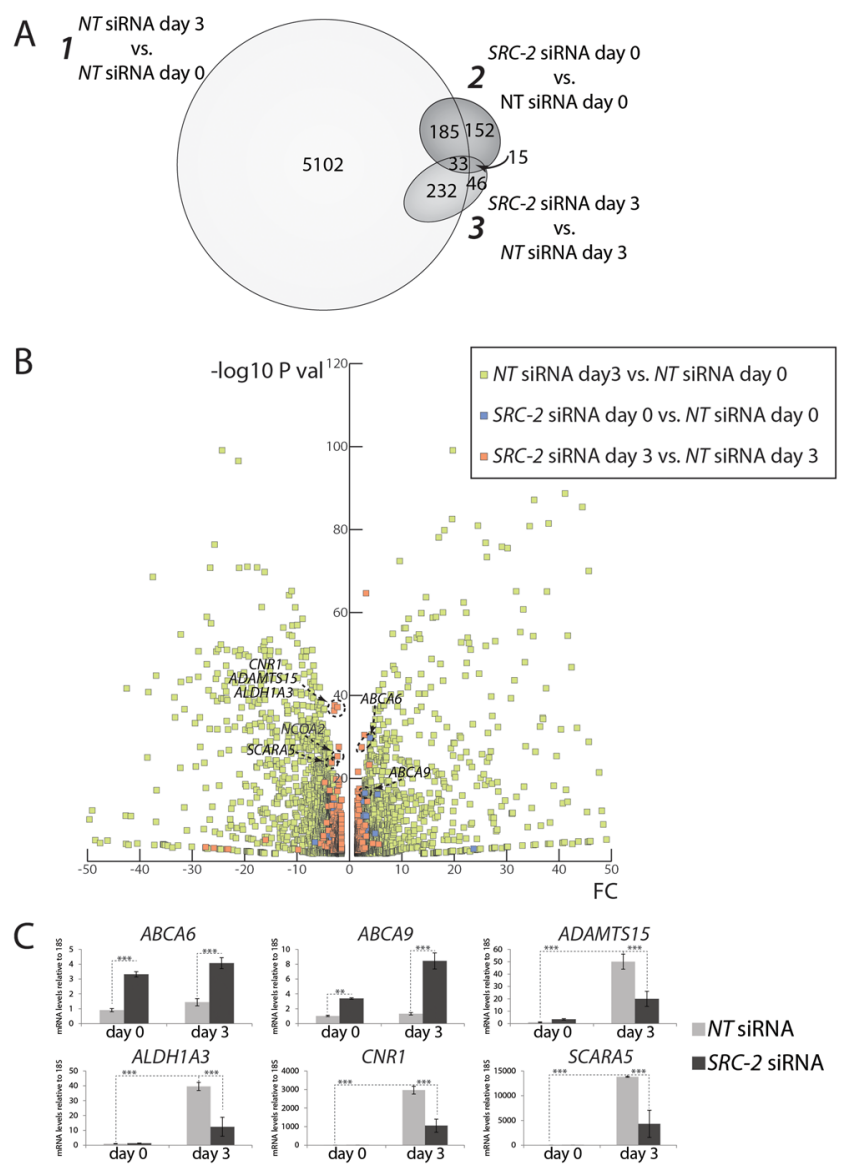

Figure 1 Global gene expression changes that occur during hESC decidualization and with SRC-2 knockdown. (A) Venn diagram displaying the numbers of genes identified by RNA-seq for which expression is significantly changed $(|F C| \geq 1.5$, FDR $<0.05)$ by: (1) decidualization; (2) by SRC-2 knockdown before the onset of decidualization or (3) by SRC-2 knockdown at day 3 of decidualization/EPC treatment. These data also include the number of overlapping and non-overlapping genes between these three datasets. (B) Volcano plot of the FC and - $\log 10 P$-value of gene expression changes detected by RNA-seq as presented in (A). For clarity, $|F C|$ cut-off has been set at 50. Genes with the highest $|\mathrm{FC}|>100$ are represented in Supplementary Fig. 2. All data can be found in Supplementary data 1. (C) Quantitative reverse transcriptase PCR analysis of a select number of genes (highlighted in (B)) that confirms the gene expression changes identified by RNA-seq profiling.

decidualization with $|\mathrm{FCs}|$ reaching as high as 8400, SRC-2 knockdown leads to gene expression changes found primarily in the -5 to +5 fold change (FC) range (Fig. 1B and Supplementary Fig. 2). The analysis of the expression changes of genes altered by both the EPC treatment (comparison 1 as shown in Fig. $1 \mathrm{~A}$ ) and the SRC-2 knockdown at either day 0 of EPC treatment (comparison 2, Fig. 1A) or day 3 of EPC treatment (comparison 3, Fig. 1A) revealed a very distinct pattern of expression change directionality. The majority of expression changes of genes altered both by knockdown of SRC-2 at day 3 of EPC treatment (comparison 3) and by EPC treatment (comparison 1) occurred in the opposite direction (i.e. if a gene was upregulated in comparison 1 , it would be downregulated in comparison 3 and vice versa) (Supplementary Fig. 3B). Conversely, SRC-2 knockdown at day 0 of EPC treatment (comparison 2) caused gene expression changes primarily in the same direction as occurs during decidualization (comparison 1) (Supplementary Fig. 3A).

As a first-line validation analysis to confirm the hESC gene expression changes due to SRC-2 knockdown as shown in the volcano plot (Fig. 1B), we used quantitative reverse transcriptase PCR analysis on an arbitrary chosen set of genes (Fig. 1C). As expected, SRC-2 knockdown resulted in the upregulation or downregulation of the following genes: ATP-binding cassette subfamily A member 6 (ABCA6), ABCA9, ADAM metallopeptidase with thrombospondin type 1 motif 15 (ADAMTS15), aldehyde dehydrogenase 1 family member A3 (ALDH1A3), cannabinoid receptor 1 (CNR1) and scavenger receptor class A member 5 (SCARA5).

Collectively, these results demonstrate that SRC-2 exerts potent coregulator control of genome-wide transcriptional reprogramming that occurs when hESCs undergo decidualization. These results provide a much needed molecular perspective to our previous studies, which demonstrated a critical functional role for this coactivator in hESC and murine uterine decidualization (Mukherjee et al. 2006, Kommagani et al. 2013).

\section{Gene expression changes dependent on SRC-2 regulate} cellular processes associated with hESC decidualization

To reveal the cellular and molecular processes controlled by SRC-2 at day 0 EPC and day 3 of EPC (the 385 and 326 genes altered by SRC-2 knockdown respectively as presented in Fig. 1A), Gene Ontology (GO) analysis with the DAVID Functional Annotation Clustering tool (Fig. 2) and Gene Set Enrichment Analysis (GSEA) (Supplementary Fig. 4) were performed. Bioinformatic analysis revealed that SRC-2 is primarily linked to the regulation of gene expression associated with cell membrane signaling and transport. Importantly, a subset of the molecular pathways and terms found to be enriched with SRC-2 knockdown have been previously implicated in the execution of the decidual progression program, such as extracellular matrix remodeling, immunomodulation and cell cycle regulation (Gellersen \& Brosens 2014).

\section{Expression of a subset of genes dependent on PGR requires SRC-2}

To identify genes that are regulated during hESC decidualization by both SRC-2 and PGR, we integrated the lists of genes that are upregulated or downregulated when SRC-2 or PGR (Mazur et al. 2015) are knocked down at day 3 of EPC treatment. Although the number of hESC genes controlled by PGR is significantly 


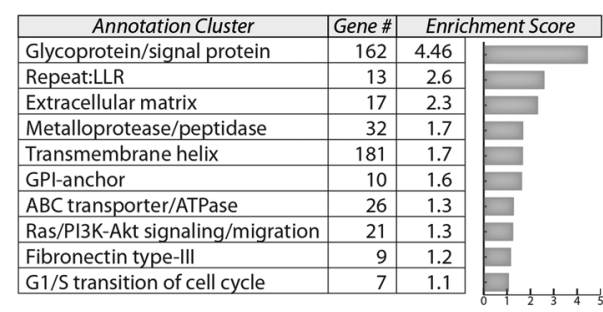

\begin{tabular}{|l|r|r|}
\hline \multicolumn{1}{|c|}{ Annotation Cluster } & Gene \# & Enrichment Score \\
\hline Glycoprotein/signal/secreted & 209 & 31.7 \\
\hline Transmembrane helix & 162 & 7.1 \\
\hline Membrane & 170 & 6.1 \\
\hline Thrombospondin, type 1 repeat & 10 & 3.6 \\
\hline PI3K-Akt signaling/ECM & 25 & 3.5 \\
\hline Fibronectin type-III & 30 & 3.3 \\
\hline Positive regulation of cell division & 7 & 2.6 \\
\hline EGF-like & 19 & 2.6 \\
\hline Immunoglobulin domain & 28 & 2.3 \\
\hline Cellular response to IL-1/TNF/FGF & 9 & 2.2 \\
\hline
\end{tabular}

greater than the number regulated by SRC-2 at day 3 EPC treatment (2503 vs. 326 genes), almost 55\% of the SRC-2 regulated genes (178 out of 326) are also regulated by PGR (Fig. 3A). Following DAVID functional annotation clustering analysis of genes that are (1) only regulated by SRC-2 (148 genes); (2) only regulated by PGR (2325 genes) or (3) regulated by both SRC-2 and PGR (178 genes), we found the overlap between SRC-2 and PGR altered genes was significantly enriched for genes involved in 'hormone activity/female pregnancy' (Fig. 3B; middle column (highlighted)). Validation of gene expression changes by qPCR (Fig. 3C) confirmed that these genes - adrenomedullin $(A D M)$, chorionic gonadotropin alpha polypeptide (CGA), insulin like growth factor 1 (IGF1), parathyroid hormone like hormone $(P T H L H)$, prolactin $(P R L)$ and urocortin 2 (UCN2) - were not only upregualted or downregulated following SRC-2 knockdown, but the expression of these genes is significantly changed during hESC decidualization (Fig. 3C).

\section{Induction of retinol transporters essential for hESC decidualization requires $S R C-2$}

Integrating genes regulated by SRC-2 and PGR with gene expression changes resulting from EPC treatment for 3 days revealed that $89 \%$ of genes controlled by both SRC-2 and PGR are also responsive to EPC treatment (Fig. 4A). Moreover, integration of this RNA-seq dataset with a previously published ChIP-seq dataset for PGR (Mazur et al. 2015) and our ChIP-seq dataset for SRC-2 showed that from the 153 potential gene targets of SRC-2, PGR and EPC, 16 of these target genes are directly bound by both SRC-2 and PGR within $25 \mathrm{~kb}$ of the gene (Fig. 4B). Interestingly, one of these target genes is stimulated by retinoic acid 6 (STRA6; Fig. 3B), which is bound by both SRC-2 and PGR on its proximal promoter region (Fig. 4C). During hESC decidualization (day 3 vs day 0 EPC treatment), STRA6 transcript levels are significantly increased, and this transcriptional induction is severely attenuated when SRC-2 levels are reduced (Fig. 4D). Apart from STRA6, we also showed that SRC-2 indirectly controls the induction of another important component of retinoid trafficking, retinolbinding protein 4 (RBP4) (Fig. 4E). Importantly, reduction of STRA6 protein levels (Supplementary Fig. 5) leads to a significant reduction in the induction of IGFBP1 and PRL (Fig. 4F), which are established molecular biomarkers of decidualization (Brosens et al. 1999). Together, our data reveal for the first time a signaling connection between SRC-2 and retinoid transport, which is required for full hESC decidualization.

\section{Discussion}

Notwithstanding the significant advances in delineating the pivotal effector signals that are critical for progesterone-dependent hESC decidualization, our knowledge of the key endometrial coregulators involved in these signaling processes remains incomplete. Using an advanced engineered mouse model, we previously demonstrated that SRC-2 abrogation results in a block in progesterone-driven endometrial decidualization, which results in pregnancy failure (Mukherjee et al. 2006, Mukherjee et al. 2007). Interestingly, forced SRC-2 overexpression in the murine uterus also blocks endometrial decidualization (Szwarc et al. 2014a), suggesting that critical controls on SRC-2 levels are necessary to maintain normal endometrial cell function (Szwarc et al. 2014b). Important from a clinical perspective, we demonstrated that SRC-2 is expressed in human endometrial tissue and essential for hESC decidualization in vitro (Mukherjee et al. 2007, Kommagani et al. 2013), providing critical translational support for observations made in the mouse. Because of the established role of SRC-2 as a pleiotropic coregulator of metabolism in other physiological systems (Stashi et al. 2014), we initially employed 
A



B

\begin{tabular}{|c|c|c|c|}
\hline & $\begin{array}{c}\text { SRC-2 siRNA day } 3 \text { vs. NT siRnA day } 3 \\
\text { only }\end{array}$ & overlap & $\begin{array}{l}\text { PGR siRNA day } 3 \text { vs. NT siRNA day } 3 \\
\text { only }\end{array}$ \\
\hline 1 & $\begin{array}{l}\text { signal peptide/Secreted/Glycoprotein/ } \\
\text { disulfide bond/glycosylation site/extracellular region }\end{array}$ & signal peptide/Glycoprotein/Secreted/Disulfide bond & $\begin{array}{l}\text { Glycoprotein/glycosylation site/signal peptide/ } \\
\text { Cell Membrane/transmembrane region/Extracellular/ } \\
\text { Cytoplasmic/Disulfide bond }\end{array}$ \\
\hline 2 & $\begin{array}{l}\text { Membrane/transmembrane region/ } \\
\text { Extracellular/Cytoplasmic }\end{array}$ & Extracellular matrix & Cell junction/Synapse/postsynaptic membrane \\
\hline 3 & $\begin{array}{l}\text { Focal (cell) achesion/Pl3K-Akt signaling pathway/ } \\
\text { ECM organization/endoplasmic reticulum lumen }\end{array}$ & $\begin{array}{l}\text { plasma membrane/Transmembrane/ } \\
\text { Cytoplasmic/Extracellular }\end{array}$ & $\begin{array}{l}\text { Hypertrophic/arrhythmogenic right ventricular/ } \\
\text { dilated cardiomyopathy }\end{array}$ \\
\hline 4 & $\begin{array}{l}\text { cellular response to interleukin-1/platelet-derived } \\
\text { growth factor stimulus/tumor necrosis factor/ } \\
\text { fibroblast growth factor stimulus }\end{array}$ & $\begin{array}{l}\text { Thrombospondin, type 1/ADAM-TS / } \\
\text { metalloendopeptidase activity }\end{array}$ & $\begin{array}{l}\text { Epidermal growth factor-like domain/Insulin-like } \\
\text { growth factor binding protein, } N \text {-terminal }\end{array}$ \\
\hline 5 & $\begin{array}{l}\text { Extracellular matrix/Protein digestion } \\
\text { and absorption/Hydroxylation }\end{array}$ & hormone activity/female pregnancy & oxidoreductase activity \\
\hline 6 & perikaryon/axon terminus/dendrite & $\begin{array}{l}\text { Classical Complement Pathway/Alternative } \\
\text { Complement Pathway/lnnate immunity/DL-receptor } \\
\text { class A/serine-type endopeptidase activity/ } \\
\text { Systemic lupus erythematosus }\end{array}$ & Fibronectin, type III \\
\hline 7 & Immunoglobulin l-set//mmunoglobulin subtype 2 & Fibronectin, type III & Basic-leucine zipper domain \\
\hline 8 & $\begin{array}{l}\text { positive regulation of cell division/cytokine- } \\
\text { mediated signaling pathway }\end{array}$ & positive regulation of JAK-STAT cascade & Calmodulin-binding \\
\hline 9 & $\begin{array}{l}\text { Malaria/positive regulation of angiogenesis/ } \\
\text { activation of MAPK activity }\end{array}$ & von Willebrand factor, type C & $\begin{array}{l}\text { Metallopeptidase/Thrombospondin, type } 1 \text { repeat/ } \\
\text { cysteine-rich }\end{array}$ \\
\hline 10 & $\begin{array}{l}\text { immune/inflammatory/cytokine activity/neutrophil } \\
\text { chemotaxis/rheumatoid arthritis/influenza A }\end{array}$ & $\begin{array}{l}\text { virus receptor activity/peptidyl-tyrosine } \\
\text { phosphorylation/leukocyte migration }\end{array}$ & $\begin{array}{l}\text { membrane receptor tyrosine kinase activity/serine- } \\
\text { threonine/tyrosine-protein kinase catalytic domain }\end{array}$ \\
\hline
\end{tabular}

C
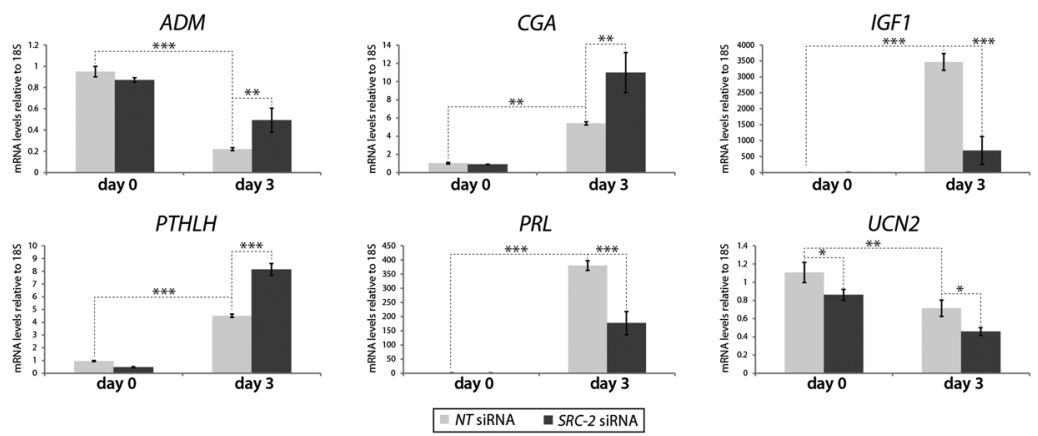

Figure 3 Expression of PGR-controlled genes involved in reproductive processes in the human endometrium that require SRC-2. (A) Venn diagram showing the number of genes for which expression is significantly changed by knockdown of SRC-2, PGR, or both SRC-2 and PGR at day 3 of EPC treatment. (B) DAVID Functional Annotation clustering of genes for which expression is changed by knockdown of SRC-2 and/or PGR (as presented in (A)). (C) Validation by quantitative reverse transcriptase PCR of gene expression changes found in the 'hormone activity/ female pregnancy' functional annotation cluster (highlighted in (B)).

metabolomic profiling to gain a firsthand mechanistic understanding of SRC-2's role in hESC decidualization (Kommagani et al. 2013). This profiling method furnished essential metabolic insight into SRC-2's role in hESC decidualization; however, SRC-2's involvement in global transcriptional reprogramming that is known to occur with progesterone-driven decidualization could not be addressed by this approach.

Therefore, to annotate the genome-wide transcriptional responses that are modulated by SRC-2 during progesterone-dependent hESC decidualization, we used here a primary cell culture model, siRNA-mediated knockdown approaches and RNA-seq and ChIP-seq technologies followed by bioinformatic analysis and validation. With an integrative analytic strategy, we found that approximately $50 \%$ of genes regulated by SRC-2 are also controlled by PGR; underscoring SRC-2's dedicated coregulator role in PGR-mediated signaling during hESC decidualization. In keeping with its pleiotropic coregulator role, SRC-2 regulates a broad spectrum of target genes during hESC decidualization, many of which encode cell membrane-associated proteins. Importantly, functional gene enrichment analysis demonstrated a significant representation of genes regulated by SRC-2 along with PGR involved in the 'hormone activity/ reproduction/pregnancy' category. Integration of RNAand ChIP-seq datasets further stratified this category of genes in terms of direct targets of both PGR and SRC-2 to reveal STRA6 as a gene target directly regulated by this NR and coregulator.

This finding is significant as STRA6 is an integral cell membrane protein that transports retinol into the cell 

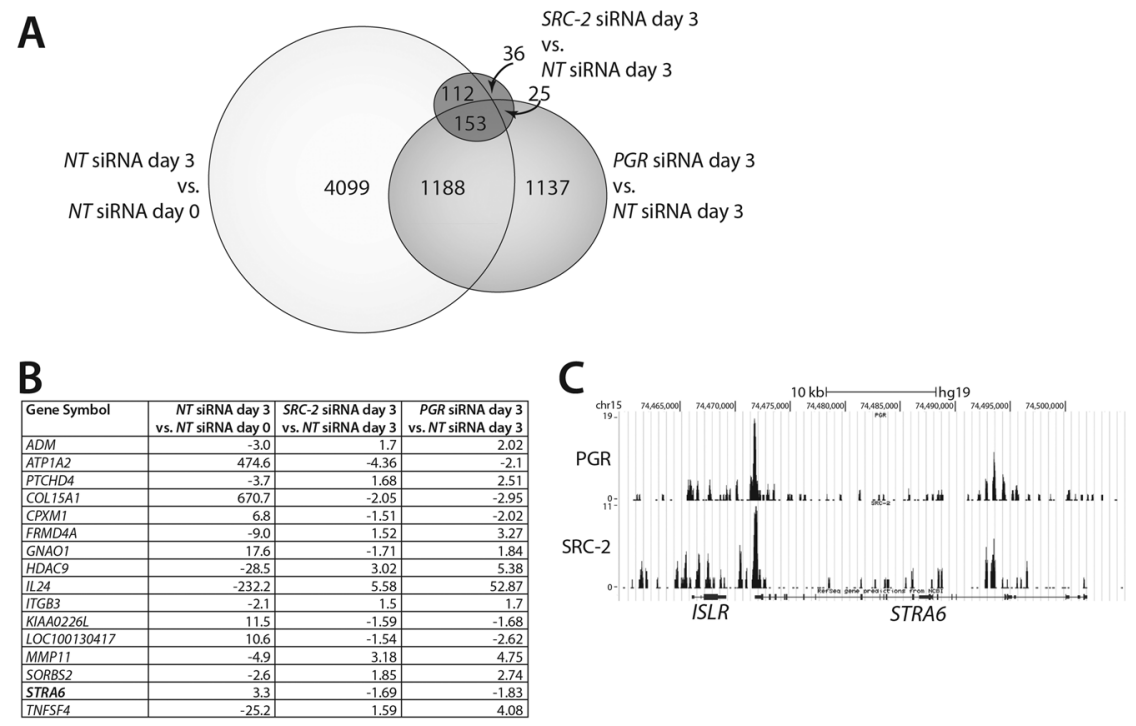

Figure 4 Induction of STRA6 requires SRC-2 and is essential for hESC decidualization. (A) Venn diagram showing the numbers and overlaps of genes with significant expression changes induced by (1) decidualization (day 3 vs day 0 of EPC treatment); (2) knockdown of SRC-2 at day 3 of EPC treatment (decidualization) and (3) knockdown of PGR at day 3 of EPC (decidualization). (B) Genes (with associated expression changes) that overlap between all three datasets detailed in (A) and are direct targets of SRC-2 and PGR (Mazur et al. 2015) as assessed by ChIP-seq.
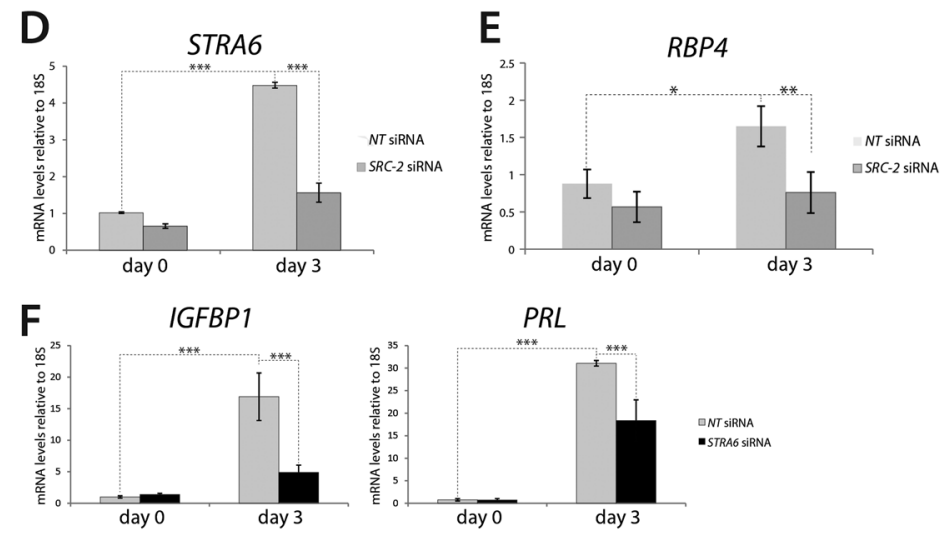

(C) ChIP-seq analysis shows binding of SRC-2 and PGR to the STRA6 promoter in hESCs treated with EPC for three days. (D) Quantitative reverse transcriptase PCR shows that STRA6 transcript levels are induced with EPC and that SRC-2 is required for this induction. (E) Induction of RBP4 RNA levels in hESCs treated with EPC for 3 days is significantly diminished with SRC-2 knockdown. (F) Quantitative reverse transcriptase PCR shows that normal induction at the RNA level of IGFBP1 and PRL (decidual biomarkers) is significantly reduced with STRA6 knockdown in hESC treated with EPC for 3 days.

for conversion into retinoic acid, which in turn acts as the ligand for retinoic acid receptor subtypes (Leid et al. 1993). Even though Stra6 knockout mice are fertile (Berry et al. 2013), the functional importance of STRA6 is strikingly different between human and rodent. In humans, STRA6 mutations leading to Matthew-Woods syndrome cause devastating phenotypes in human not seen in the mouse knockout, underscoring the functional divergence of STRA6 between human and rodent (Golzio et al. 2007, Pasutto et al. 2007). Retinoid signaling is known to control cell differentiation, proliferation and cell survival in numerous physiological and pathological contexts (Jiang et al. 2018). In the case of the endometrial stromal cell, a number of studies have shown that retinoid transport, metabolism and activity are essential for normal cellular function and that the observed perturbation of retinoid signaling in endometriotic cells may explain the decreased ability of these cells to decidualize (Pavone et al. 2011, Pierzchalski et al. 2014). In particular, STRA6 expression levels, previously shown to be dependent on PGR and responsible for retinoic acid transport in normal hESCs (Pavone et al. 2010), are strikingly reduced in endometriotic cells (Pavone et al. 2011). Our studies also show that the normal induction of RBP4 expression during $\mathrm{hESC}$ decidualization is critically dependent on SRC-2. Compared to hESCs, levels of RBP4 have also been shown to be severely reduced in endometriotic stromal cells (Pavone et al. 2017). Interestingly, other studies have demonstrated that RBP4 acts as a paracrine factor when induced and secreted from hESCs during decidualization (Pavone et al. 2017). Secreted from hESCs, RBP4 is thought to act on adjacent epithelial cells to stimulate conversion of estradiol to estrone (Cheng et al. 2007), thereby reducing estradiol levels that can be detrimental to normal endometrial growth homeostasis and function (Cha et al. 2012). Apart from uncovering a novel convergence of SRC2, PGR and retinoid signaling that is critical for hESC decidualization, two important questions emerge for future investigation: (1) what other transcription factors (NR and/or non-NR) - apart from PGR - interact with SRC-2 to control the hESC transcriptome during decidualization? And (2) what is the makeup of the transcriptional interactome that enables SRC-2 to modulate transcriptional responses in decidualizing hESCs?

In sum, transcriptomic analysis described herein provides a much required global molecular perspective 
on SRC-2's critical role in progesterone-dependent hESC decidualization and represents a powerful informational resource with which to uncover novel signaling paradigms for SRC-2 action in uterine function.

\section{Supplementary data}

This is linked to the online version of the paper at https://doi.org/10.1530/REP-18-0282.

\section{Declaration of interest}

The authors declare that there is no conflict of interest that could be perceived as prejudicing the impartiality of the research reported.

\section{Funding}

This research was supported in part by the Genomic and RNA Profiling Core at Baylor College of Medicine with funding from the NIH NCl grant (P30CA125123 to L D W); and National Institutes of Health (NIH)/National Institute of Child Health and Human Development (NICHD) grants: R00 HD080742 to R K; RO1 HD07857 to B W O; and RO1 HD-042311 to J P L.

\section{Acknowledgments}

The authors thank Jie Li, Yan Ying and Rong Zhao for their technical expertise.

\section{References}

Anders S, Pyl PT \& Huber W 2015 HTSeq - a Python framework to work with high-throughput sequencing data. Bioinformatics 31 166-169. (https://doi.org/10.1093/bioinformatics/btu638)

Benjamini Y \& Hochberg Y 1995 Controlling the false discovery rate: a practical and powerful approach to multiple testing. Journal of Royal Statistical Society 57 289-300.

Berry DC, Jacobs H, Marwarha G, Gely-Pernot A, O'Byrne SM, DeSantis D, Klopfenstein M, Feret B, Dennefeld C, Blaner WS et al. 2013 The STRA6 receptor is essential for retinol-binding protein-induced insulin resistance but not for maintaining vitamin $\mathrm{A}$ homeostasis in tissues other than the eye. Journal of Biological Chemistry 288 24528-24539. (https:// doi.org/10.1074/jbc.M113.484014)

Blesa D, Ruiz-Alonso M \& Simon C 2014 Clinical management of endometrial receptivity. Seminars in Reproductive Medicine 32 410-413. (https://doi.org/10.1055/s-0034-1376360)

Brosens JJ, Hayashi N \& White JO 1999 Progesterone receptor regulates decidual prolactin expression in differentiating human endometrial stromal cells. Endocrinology 140 4809-4820. (https://doi.org/10.1210/ endo.140.10.7070)

Carson DD, Bagchi I, Dey SK, Enders AC, Fazleabas AT, Lessey BA \& Yoshinaga K 2000 Embryo implantation. Developmental Biology 223 217-237. (https://doi.org/10.1006/dbio.2000.9767)

Cha J, Sun X \& Dey SK 2012 Mechanisms of implantation: strategies for successful pregnancy. Nature Medicine 18 1754-1767. (https://doi. org/10.1038/nm.3012)

Chambers GM, Hoang VP, Sullivan EA, Chapman MG, Ishihara O, ZegersHochschild F, Nygren KG \& Adamson GD 2014 The impact of consumer affordability on access to assisted reproductive technologies and embryo transfer practices: an international analysis. Fertility and Sterility $\mathbf{1 0 1}$ 191-198.e194. (https://doi.org/10.1016/j.fertnstert.2013.09.005)
Cheng YH, Imir A, Fenkci V, Yilmaz MB \& Bulun SE 2007 Stromal cells of endometriosis fail to produce paracrine factors that induce epithelial 17beta-hydroxysteroid dehydrogenase type 2 gene and its transcriptional regulator Sp1: a mechanism for defective estradiol metabolism. American Journal of Obstetrics and Gynecology 196 391.e391-397. e391; discussion 391.e397-398.e397.

Cloke B, Huhtinen K, Fusi L, Kajihara T, Yliheikkila M, Ho KK, Teklenburg G, Lavery S, Jones MC, Trew G et al. 2008 The androgen and progesterone receptors regulate distinct gene networks and cellular functions in decidualizing endometrium. Endocrinology 149 4462-4474. (https:// doi.org/10.1210/en.2008-0356)

Dobin A, Davis CA, Schlesinger F, Drenkow J, Zaleski C, Jha S, Batut P, Chaisson M \& Gingeras TR 2013 STAR: ultrafast universal RNAseq aligner. Bioinformatics 29 15-21. (https://doi.org/10.1093/ bioinformatics/bts635)

Gehin M, Mark M, Dennefeld C, Dierich A, Gronemeyer H \& Chambon P 2002 The function of TIF2/GRIP1 in mouse reproduction is distinct from those of SRC-1 and p/CIP. Molecular and Cellular Biology 22 5923-5937. (https://doi.org/10.1128/MCB.22.16.5923-5937.2002)

Gellersen B \& Brosens JJ 2014 Cyclic decidualization of the human endometrium in reproductive health and failure. Endocrine Reviews 35 851-905. (https://doi.org/10.1210/er.2014-1045)

Gellersen B, Brosens IA \& Brosens JJ 2007 Decidualization of the human endometrium: mechanisms, functions, and clinical perspectives. Seminars in Reproductive Medicine 25 445-453. (https://doi. org/10.1055/s-2007-991042)

Golzio C, Martinovic-Bouriel J, Thomas S, Mougou-Zrelli S, GrattaglianoBessieres B, Bonniere M, Delahaye S, Munnich A, Encha-Razavi F, Lyonnet S et al. 2007 Matthew-Wood syndrome is caused by truncating mutations in the retinol-binding protein receptor gene STRA6. American Journal of Human Genetics 80 1179-1187. (https://doi. org/10.1086/518177)

Greil AL, Slauson-Blevins K \& McQuillan J 2010 The experience of infertility: a review of recent literature. Sociology of Health and Illness 32 140-162. (https://doi.org/10.1111/j.1467-9566.2009.01213.x)

Huang da W, Sherman BT \& Lempicki RA 2009 Systematic and integrative analysis of large gene lists using DAVID bioinformatics resources. Nature Protocols 4 44-57. (https://doi.org/10.1038/nprot.2008.211)

Jiang Y, Chen L, Taylor RN, Li C \& Zhou X 2018 Physiological and pathological implications of retinoid action in the endometrium. Journal of Endocrinoloy 236 R169-R188. (https://doi.org/10.1530/JOE-17-0544)

Kommagani R, Szwarc MM, Kovanci E, Gibbons WE, Putluri N, Maity S, Creighton CJ, Sreekumar A, DeMayo FJ, Lydon JP et al. 2013 Acceleration of the glycolytic flux by steroid receptor coactivator-2 is essential for endometrial decidualization. PLoS Genetics 9 e1003900. (https://doi.org/10.1371/journal.pgen.1003900)

Kommagani R, Szwarc MM, Vasquez YM, Peavey MC, Mazur EC, Gibbons WE, Lanz RB, DeMayo FJ \& Lydon JP 2016 The promyelocytic leukemia zinc finger transcription factor is critical for human endometrial stromal cell decidualization. PLoS Genetics 12 e1005937. (https://doi. org/10.1371/journal.pgen.1005937)

Leid M, Kastner P, Durand B, Krust A, Leroy P, Lyons R, Mendelsohn C, Nagpal S, Nakshatri H, Reibel C et al. 1993 Retinoic acid signal transduction pathways. Annals of the New York Academy of Sciences 684 19-34. (https://doi.org/10.1111/j.1749-6632.1993.tb32268.x)

Liberzon A, Birger C, Thorvaldsdottir H, Ghandi M, Mesirov JP \& Tamayo P 2015 The Molecular Signatures Database (MSigDB) hallmark gene set collection. Cell Systems 1 417-425. (https://doi.org/10.1016/j. cels.2015.12.004)

Lydon JP, DeMayo FJ, Funk CR, Mani SK, Hughes AR, Montgomery CA Jr, Shyamala G, Conneely OM \& O'Malley BW 1995 Mice lacking progesterone receptor exhibit pleiotropic reproductive abnormalities. Genes and Development 9 2266-2278. (https://doi.org/10.1101/ gad.9.18.2266)

Macklon NS, Geraedts JP \& Fauser BC 2002 Conception to ongoing pregnancy: the 'black box' of early pregnancy loss. Human Reproduction Update 8 333-343. (https://doi.org/10.1093/humupd/8.4.333)

Mazur EC, Vasquez YM, Li X, Kommagani R, Jiang L, Chen R, Lanz RB, Kovanci E, Gibbons WE \& DeMayo FJ 2015 Progesterone receptor transcriptome and cistrome in decidualized human endometrial stromal cells. Endocrinology 156 2239-2253. (https://doi.org/10.1210/ en.2014-1566) 
Mukherjee A, Soyal S, Fernandez-Valdivia R, Gehin M, Chambon P, Demayo F, Lydon J \& O'Malley B 2006 Steroid receptor coactivator 2 is critical for progesterone-dependent uterine function and mammary morphogenesis in the mouse. Molecular and Cellular Biology 26 6571-6583. (https://doi.org/10.1128/MCB.00654-06)

Mukherjee A, Amato P, Allred DC, DeMayo FJ \& Lydon JP 2007 Steroid receptor coactivator 2 is required for female fertility and mammary morphogenesis: insights from the mouse, relevance to the human. Nuclear Receptor Signaling 5 e011.

Norwitz ER, Bonney EA, Snegovskikh VV, Williams MA, Phillippe M, Park JS \& Abrahams VM 2015 Molecular regulation of parturition: the role of the decidual clock. Cold Spring Harbor Perspectives in Medicine 5 a023143. (https://doi.org/10.1101/cshperspect.a023143)

Onate SA, Tsai SY, Tsai MJ \& O'Malley BW 1995 Sequence and characterization of a coactivator for the steroid hormone receptor superfamily. Science 270 1354-1357. (https://doi.org/10.1126/ science.270.5240.1354)

Pasutto F, Sticht H, Hammersen G, Gillessen-Kaesbach G, Fitzpatrick DR, Nurnberg G, Brasch F, Schirmer-Zimmermann H, Tolmie JL, Chitayat D et al. 2007 Mutations in STRA6 cause a broad spectrum of malformations including anophthalmia, congenital heart defects, diaphragmatic hernia, alveolar capillary dysplasia, lung hypoplasia, and mental retardation. American Journal of Human Genetics 80 550-560. (https://doi. org/10.1086/512203)

Pavone ME, Dyson M, Reirstad S, Pearson E, Ishikawa H, Cheng YH \& Bulun SE 2011 Endometriosis expresses a molecular pattern consistent with decreased retinoid uptake, metabolism and action. Human Reproduction 26 2157-2164. (https://doi.org/10.1093/humrep/der172)

Pavone ME, Malpani S, Dyson M \& Bulun SE 2017 Altered retinoid signaling compromises decidualization in human endometriotic stromal cells. Reproduction 154 107-116. (https://doi.org/10.1530/REP-16-0592)

Pavone ME, Reierstad S, Sun H, Milad M, Bulun SE \& Cheng YH 2010 Altered retinoid uptake and action contributes to cell survival in endometriosis. Journal of Clinical Endocrinology and Metabolism 95 E300-E309. (https://doi.org/10.1210/jc.2010-0459)

Pierzchalski K, Taylor RN, Nezhat C, Jones JW, Napoli JL, Yang G, Kane MA \& Sidell N 2014 Retinoic acid biosynthesis is impaired in human and murine endometriosis. Biology of Reproduction 91 84. (https://doi. org/10.1095/biolreprod.114.119677)

Robinson MD, McCarthy DJ \& Smyth GK 2010 edgeR: a Bioconductor package for differential expression analysis of digital gene expression data. Bioinformatics 26 139-140. (https://doi.org/10.1093/ bioinformatics/btp616)

Stashi E, York B \& O'Malley BW 2014 Steroid receptor coactivators: servants and masters for control of systems metabolism. Trends in
Endocrinology and Metabolism 25 337-347. (https://doi.org/10.1016/j. tem.2014.05.004)

Szwarc MM, Kommagani R, Jeong JW, Wu SP, Tsai SY, Tsai MJ, O'Malley BW, DeMayo FJ \& Lydon JP 2014a Perturbing the cellular levels of steroid receptor coactivator-2 impairs murine endometrial function. PLOS ONE 9 e98664. (https://doi.org/10.1371/journal.pone.0098664)

Szwarc MM, Kommagani R, Lessey BA \& Lydon JP 2014b The p160/steroid receptor coactivator family: potent arbiters of uterine physiology and dysfunction. Biology of Reproduction 91 122. (https://doi.org/10.1095/ biolreprod.114.125021)

Szwarc MM, Hai L, Gibbons WE, Peavey MC, White LD, Mo Q, Lonard DM, Kommagani R, Lanz RB, DeMayo FJ et al. 2018 Human endometrial stromal cell decidualization requires transcriptional reprogramming by PLZF. Biology of Reproduction 98 15-27. (https://doi.org/10.1093/biolre/iox161)

Torchia J, Rose DW, Inostroza J, Kamei Y, Westin S, Glass CK \& Rosenfeld MG 1997 The transcriptional co-activator p/CIP binds CBP and mediates nuclear-receptor function. Nature 387 677-684. (https:// doi.org/10.1038/42652)

Voegel JJ, Heine MJ, Zechel C, Chambon P \& Gronemeyer H 1996 TIF2, a $160 \mathrm{kDa}$ transcriptional mediator for the ligand-dependent activation function AF-2 of nuclear receptors. EMBO Journal 15 3667-3675.

Wang H \& Dey SK 2006 Roadmap to embryo implantation: clues from mouse models. Nature Reviews Genetics 7 185-199. (https://doi. org/10.1038/nrg1808)

Wilcox AJ, Weinberg CR, O'Connor JF, Baird DD, Schlatterer JP, Canfield RE, Armstrong EG \& Nisula BC 1988 Incidence of early loss of pregnancy. New England Journal of Medicine 319 189-194. (https://doi. org/10.1056/NEJM198807283190401)

WMA 1966 WMA Declaration of Helsinki serves as guide to physicians. California Medicine 105 149-150.

Xu J, Wu R-C \& O'Malley B 2009 Normal and cancer-related functions of the p160 steroid receptor co-activator (SRC) family. Nature Reviews Cancer 9 615-630. (https://doi.org/10.1038/nrc2695)

Zinaman MJ, Clegg ED, Brown CC, O'Connor J \& Selevan SG 1996 Estimates of human fertility and pregnancy loss. Fertility and Sterility $\mathbf{6 5}$ 503-509. (https://doi.org/10.1016/S0015-0282(16)58144-8)

Received 31 May 2018

First decision 3 July 2018

Revised manuscript received 17 July 2018

Accepted 2 August 2018 